\title{
Evaluation of Ovarian Potential for in Vitro Embryo Production on Indian Buffaloes
}

\author{
Eias Elzein I Osman ${ }^{1 *}$, Sharma RK² and Majdi E Badawi ${ }^{3}$ \\ ${ }^{1}$ Department of clinical studies, Faculty of Veterinary Science, University of Nyala, A43, Nyala, Sudan \\ 2Physiology and Reproduction Division, Central Institute for Research on Buffaloes, Sirsa Rd, Sector 14, Hisar, Haryana 125001, India \\ 3Department of medicine and animal surgery, College of Veterinary Medicine, Sudan University of Sciences and Technology, \\ Khartoum, Sudan
}

\section{*Corresponding Author \\ Eias Elzein I Osman}

\section{Article History}

Received: 22.10.2019

Accepted: 31.10.2019

Published: 11.11.2019

\begin{abstract}
The aim of this study was to evaluate the effect of $\mathrm{CL}$, ovary weight and ovary size, on follicular population, oocytes recovery, oocytes grades, oocytes index and cleavage rate on Indian buffalos. A total of 296 buffalo ovaries were collected from slaughterhouse and transported to laboratory for determination of ovaries weight, length, width, thickness, follicular population and oocytes grades, oocytes index and cleavage rate. The results obtained revealed that the number of small and large follicles were significantly higher in ovaries having weight more than $5 \mathrm{~g}$ as compared to ovaries weight between $3-5 \mathrm{~g}$ and less than $3 \mathrm{~g}$. The number of small follicles in large size ovaries was significantly higher as compared to small size ovaries. The mean number of oocytes recovery, number of oocytes for IVEP and number of cleavage, obtained from ovaries with CL was lower than that of ovaries without $\mathrm{CL}$. No significant difference observed between presence and absence of CL, follicular population and oocytes grades.
\end{abstract}

Keywords: Indian buffalo, Ovary, follicular population, oocytes recovery, oocytes grades, embryo.

\section{INTRODUCTION}

Biotechnologies are being used in animal and agriculture to improve production, and to develop specialized food products and pharmaceutical products. Manipulations of reproductive processes are necessary to accomplish these goals. In this direction dairy industry was perfected the application of the first reproductive biotechnology is artificial insemination (Al). The dairy industry also remains the number one user of embryo transfer technology (ET). In addition, recently the dairy industry has also adopted the field of in vitro embryo production [1]. In vitro Embryo Production (IVEP) is reproductive techniques that supplement Al in the genetic improvement of local cattle breeds [2]. IVEP permits the preservation of genetic potential of sub-fertile or dead animals [3] by the creation of a gene bank with oocytes recovered from slaughterhouses [4] for the improvement of livestock productivity [5]. The embryo production is carried out through a combination of techniques of collection of immature oocytes, in vitro maturation (IVM), fertilization (IVF) and culture (IVC). However, the significantly contributing factors in the success of IVEP are the quality and number of collected oocytes [6]. In addition, in vitro production technologies not only help in production of high genetic merit animals, but also consider an excellent source of embryos for emerging biotechnologies such as embryo sexing, cloning, nuclear transfer, transgenesis etc. Furthermore, it allows analyzing developmental potential of embryos, including the pattern of gene expression, epigenetic modifications and cytogenetic disorders during the development [7]. Early stages of bovine embryo development show many similarities with human embryos. Therefore, bovine embryos are used as a model organism [8]. Also, IVP can be used to rescue and save irreplaceable genetic material following slaughter for infectious disease control or culling for other reasons [9]. There is no information available about evaluation of ovarian potential for In Vitro Embryo Production in study area. The objective of this study was to evaluate of ovarian potential for In Vitro Embryo Production on Indian buffaloes.

Copyright @ 2019: This is an open-access article distributed under the terms of the Creative Commons Attribution license which permits unrestricted use, distribution, and reproduction in any medium for non commercial use (NonCommercial, or CC-BY-NC) provided the original author and source are credited. 


\section{Materials ANd Methods \\ Study Area}

The present research was conducted in year 2018 - 2019 at Central Institute for Research on Buffalo, Hisar Haryana, India, located between Latitude: 2909'14" N Longitude: 75²3'22" E and Elevation above sea level: $216 \mathrm{~m}$.

\section{Experiment Design \\ Medium Preparation}

All chemicals and media used in the present study were obtained from Sigma Aldrich (St. Louis, MO, USA), and the ware plastic was from Falcon (Paignton, UK), unless stated otherwise. Media and reagents were prepared using standard protocol of embryo laboratory technique at Central Institute for Research on buffaloes, India under aseptic conditions. All media were filtered using $0.22 \mu \mathrm{m}$ pore size filter (Durapure ${ }^{\circledR}$ membrane filter, Carrigtwohill, Ireland) and culture medium was routinely equilibrated in incubator at $38.5^{\circ} \mathrm{C}$ with $5 \% \mathrm{CO}_{2}$ in humidified air for at least $2 \mathrm{hrs}$ before use.

\section{Ovaries Collection}

Two hundred ninety six buffalo ovaries were collected immediately after slaughtering from Delhi slaughterhouse and transported to the laboratory in an insulated container containing $0.9 \%$ normal saline with antibiotics $400 \mathrm{IU} / \mathrm{ml}$ penicillin and $500 \mu \mathrm{g} / \mathrm{ml}$ streptomycin at $32-37^{\circ} \mathrm{C}$ within $4-5 \mathrm{~h}$. In laboratory, all tissues attached to ovaries were removed and all ovaries were washed twice in saline solution containing antibiotics [10]. After wash all ovaries were classified into two groups: group ovaries with $\mathrm{CL}$ and without CL.

\section{Determination of Varies Diameters Length}

The length of the ovary was taken as the distance from anterior pole to posterior pole along an axis parallel to the ovarian mesenterial attachment expressed in centimeter [11].

\section{Width} centimeter [12].

Width of the ovary was taken as the greater distance from the medial to the lateral surfaces or borders expressed in

\section{Thickness}

Thickness of the ovary was recorded as the greatest distance along an axis vertical to the longitudinal axis (base) at its center or distance from attached to the free borders expressed in centimeter [13].

Weight

Weight of the ovary was taken on the electronic balance and expressed in gram [14].

\section{Follicular Population}

The visible follicles were counted and follicle size was measured with electronic Vernier calipers. Follicles were classified into 3 categories: small $(<3 \mathrm{~mm})$, medium $(3$ to $8 \mathrm{~mm})$ and large $(>8 \mathrm{~mm})$ [15].

\section{Oocytes Collection}

Oocytes were collected by aspiration of surface follicles (2-8 mm diameter) using 18-gauge disposable needle attached to a $10 \mathrm{ml}$ syringe in aspiration medium consisting of TCM-199 and $0.6 \%$ (v/w) bovine serum albumin (BSA). The follicular fluid was collected in tube and kept for 15 minutes. The sediment was collected in $60 \mathrm{~mm}$ petri dish and oocytes were searched under stereo zoom microscope [10].

\section{Oocytes Grading}

The oocytes were graded as: grade A: having evenly granulated homogenous ooplasm with cumulus cells more than 4 compact layers, grade B: having evenly granulated homogenous ooplasm with 2 to 3 layers of cumulus cells, grade C: having evenly granulated homogenous ooplasm with less compact cumulus cells and grade D: having irregular dark ooplasm and highly expanded cumulus cells. Oocytes selected as grade A and B for IVM [16].

\section{Oocyte recovery rate per ovary}

The oocyte recovery rate was calculated by following formula: ORR = (No of recovered oocytes / total No of ovaries) [17].

\section{Oocyte Index}

It was calculated as an index using the formula [(G I $\times 1+G$ II $\times 2+G$ III $\times 3+G$ IV $\times 4) /$ Total number of oocytes recovered] as described by [15]. Index values that approach one reflected good quality oocytes. 


\section{In Vitro Maturation of Oocytes}

Oocytes were washed three times with the washing medium (TCM-199+10\% FBS $+0.81 \mathrm{mM}$ sodium pyruvate $+50 \mu \mathrm{g} / \mathrm{ml}$ gentamycin sulphate) and then twice with the IVM medium (TCM-199+10\% FBS $+5 \mu \mathrm{g} / \mathrm{ml}$ porcine $\mathrm{FSH}+1 \mu \mathrm{g} / \mathrm{ml}$ estradiol-17 $\beta+0.81$ $\mathrm{mM}$ sodium pyruvate $+5 \%$ buffalo follicular fluid $+50 \mu \mathrm{g} / \mathrm{ml}$ gentamycin sulphate). The washed cumulus oophorus complexes were then placed in 80- $\mu$ droplets (15-20 oocytes/droplet) of the IVM medium, covered with sterile paraffin oil, in a $35 \mathrm{~mm}$ Petri dish (Becton, Dickinson and Co., Lincoln Park, NJ, USA) and cultured for $24 \mathrm{~h}$ in a $\mathrm{CO}_{2}$ incubator $\left(5 \% \mathrm{CO}_{2}\right.$ in air, $90-95 \%$ relative humidity) at $38.5^{\circ} \mathrm{C}$ [10]. After $24 \mathrm{~h}$ of incubation the maturation of oocytes was assessed based on the degree of cumulus expansion. Expansion of COCs was characterized by its sticky nature and enlargement of the cumulus mass to at least 2-3 diameters from the zona pellucida [18].

\section{In Vitro Fertilization}

The matured oocytes were washed three times in BO medium having $10 \mu \mathrm{g} / \mathrm{ml}$ heparin, $137.0 \mu \mathrm{g} / \mathrm{ml}$ sodium pyruvate and $1.942 \mathrm{mg} / \mathrm{ml}$ caffeine sodium benzoate then transferred to $50 \mu \mathrm{L}$ droplets (15-20 oocytes/droplet) of the IVF medium (BO medium containing $10 \mathrm{mg} / \mathrm{ml}$ fatty acid-free BSA).There after two straws of frozen-thawed ejaculated buffalo semen were washed twice with BO medium. The spermatozoa in $50 \mu \mathrm{L}$ of the IVF medium ( 3 million spermatozoa/ $\mathrm{ml}$ ) were then added to the droplets containing the oocytes, covered with sterile mineral oil and placed in a $\mathrm{CO}_{2}$ incubator $\left(5 \% \mathrm{CO}_{2}\right.$ in air) for $18 \mathrm{~h}$ at $38.5^{\circ} \mathrm{C}$ [10].

\section{In Vitro culture of fertilized oocytes}

Presumptive zygotes were denuded from cumulus cells and the extra spermatozoa by gentle pipetting and washed three times in IVC washing medium ( $T_{2}$ ) supplemented with $1 \%$ fatty acid-free bovine serum albumin (BSA). Then fertilized oocytes were cultured in IVC (Research Vitro Cleave Medium (K-RVCL-50; Cook, Brisbane, Queensland, Australia) by making two to three droplets in $35 \mathrm{~mm}$ petridish and overlaid with mineral oil, at $38.5{ }^{\circ} \mathrm{C}$ and $5 \% \mathrm{CO}_{2}$ in a humidified incubator for 8 days [10].

Cleavage embryos were identified according to their cell number during specific time as 1 - cell on day 1, 2-cells on day 2, 4cells on day 3, 8-cells on day 4, 16-cells on day 5 as well as morula and blastocyst stages on day 6 and 7 respectively [19].

\section{Cleavage Rate}

The cleavage rate was calculated as follows: Cleavage rate $(C R)=$ number of cleavage / total of oocytes inseminated $X 100$

\section{Blastocyst Rate}

The blastocyst rate was calculated as follows: Blastocyst rate = number of Blastocyst $/$ total of oocytes inseminated X 100 .

\section{Statistical Analysis}

The study data were analyzed by Student t- test analysis using SPSS Version 18. Statistically significant confidence interval was taken as $\mathrm{P}<0.05$.

\section{RESULTS}

Effect of presence and absence of $\mathrm{CL}$, ovary weight and size on follicular population:

The effects of presence and absence of $\mathrm{CL}$, weight and size of ovary on follicular population are presented in Table-1. No significant difference was observed between ovaries with $\mathrm{CL}$ and ovaries without $\mathrm{CL}$ on follicular population. On the other hand, the number of small $(1.76 \pm 0.37)$ and large follicles $(0.41 \pm 0.51)$ found significantly higher $(P<0.05)$ numbers in ovaries having weight more than $5 \mathrm{~g}$ as compared to ovaries weight between $3-5 \mathrm{~g}$ and less than $3 \mathrm{~g}$. Otherwise, no significant difference was observed between number of medium follicles and ovaries weight. The average number of follicles per ovary was found significantly higher $(P<0.05)$ in ovaries having weight more than $5 \mathrm{~g}(2.59 \pm 0.48)$ as compared to ovaries had weight between $3-5 \mathrm{~g}(2.22 \pm 0.14)$ and less than $3 \mathrm{~g}$ $(1.80 \pm 0.10)$ respectively. This effect was due to high number of small and large follicles in group ovaries of weight more than $5 \mathrm{~g}$. Upon comparison of ovary size, we found that the number of small follicles in large size ovaries $(1.43 \pm 0.12)$ was significantly higher $(P<0.05)$ as compared to small size ovaries $(0.90 \pm 0.10)$. Overall, the average number of follicles per ovary in large size ovaries $(2.25 \pm 0.13)$ was shown significantly higher $(P<0.05)$ than small size ovaries $(1.76 \pm 0.10)$. This effect was owing to more number of small follicles in group. Otherwise no significant difference was observed between number of medium, large follicles and ovary size.

\section{Effect of presence and absence of $\mathrm{CL}$ on oocytes grades}

The effect of presence and absence of CL on oocyte grade is presented in table 2. The results showed that there is no significant difference observed between presence and absence of $C L$ and oocytes grades.

\section{Effect of present or absent of CL on oocytes recovery, oocytes index, cleavage and blastocyst rates}

The effect of $\mathrm{CL}$ on oocytes recovery, oocytes index, cleavage and blastocyst rates are presented in table 3 . The result showed the mean number of oocytes recovery obtained from ovaries with CL (145) was lower than that of ovaries without CL (335). 
The mean number of cleavage obtained from ovaries with $\mathrm{CL}(23)$ was lower as compared with those without $\mathrm{CL}$ (55). Otherwise, the oocytes recovery per ovary, oocytes index, percentages of cleavage and blastocyst were not different between groups.

Table-1: Means ( $\pm \mathrm{SE}$ ) values of $\mathrm{CL}$, ovary weight and ovary size:

\begin{tabular}{|l|l|c|c|c|c|c|}
\hline & & \multicolumn{3}{c|}{ Number of follicles } & \\
\hline \multicolumn{2}{|c|}{ Factors } & No. of ovaries & Small & Medium & Large & Average number of follicle lovary \\
\hline \multirow{4}{*}{$\mathrm{CL}$} & Present & 109 & $1.26 \pm 0.14$ & $0.52 \pm 0.09$ & $0.28 \pm 0.05$ & $2.06 \pm 0.15$ \\
\cline { 2 - 7 } & Absent & 187 & $1.15 \pm 0.1$ & $0.56 \pm 0.07$ & $0.30 \pm 0.04$ & $2.01 \pm 0.11$ \\
\cline { 2 - 7 } & $\mathbf{P}<\mathbf{0 . 0 5}$ & - & .519 & .744 & .817 & .763 \\
\hline \multirow{4}{*}{ Ovary weight(g) } & $<3$ & 147 & $1.01 \pm 0.11^{\mathrm{c}}$ & $0.57 \pm 0.08$ & $0.22 \pm 0.04 \mathrm{c}$ & $1.80 \pm 0.10^{\mathrm{c}}$ \\
\cline { 2 - 7 } & $3-5$ & 132 & $1.32 \pm 0.12^{\mathrm{b}}$ & $0.54 \pm 0.09$ & $0.36 \pm 0.05^{\mathrm{b}}$ & $2.22 \pm 0.14^{\mathrm{b}}$ \\
\cline { 2 - 7 } & $>5$ & 17 & $1.76 \pm 0.37^{\mathrm{a}}$ & $0.41 \pm 0.26$ & $0.41 \pm 0.51^{\mathrm{a}}$ & $2.59 \pm 0.48^{\mathrm{a}}$ \\
\cline { 2 - 7 } & $\mathbf{P}<\mathbf{0 . 0 5}$ & - & .034 & .808 & .050 & .015 \\
\hline \multirow{3}{*}{ Ovary size(cm) } & Small size & 134 & $0.90 \pm 0.10^{\mathrm{b}}$ & $0.60 \pm 0.08$ & $0.26 \pm 0.04$ & $1.76 \pm 0.10^{\mathrm{b}}$ \\
\cline { 2 - 7 } & Large size & 162 & $1.43 \pm 0.12^{\mathrm{a}}$ & $0.51 \pm 0.08$ & $0.32 \pm 0.05$ & $2.25 \pm 0.13^{\mathrm{a}}$ \\
\cline { 2 - 7 } & $\mathbf{P}<\mathbf{0 . 0 5}$ & - & .001 & .427 & .342 & .004 \\
\hline
\end{tabular}

$a, b, c$ in each column different letters $(a, b)$ indicated significant difference between group $(p<0.05)$. No =number $\quad C L=$ corpus luteum $S E=$ Standard Error $\mathrm{g}=$ gram $\mathrm{cm}=$ centimeter

Table-2: Effect of presence or absence of CL (Means \pm SE) on oocytes grades

\begin{tabular}{|c|l|c|c|c|c|c|c|}
\hline \multicolumn{2}{|c|}{} & \multicolumn{3}{c|}{ Oocytes grades } & IV & Selected oocytes for IVEP. I and II \\
\hline \multicolumn{2}{|c|}{ Factors } & No. of ovaries & I & II & III & IV & $0.66 \pm 0.28$ \\
\hline \multirow{3}{*}{ CL } & Present & 109 & $0.25 \pm 0.11$ & $0.41 \pm 0.18$ & $0.62 \pm 0.38$ & $0.05 \pm 0.03$ & $1.11 \pm 0.78$ \\
\cline { 2 - 8 } & Absent & 187 & $0.27 \pm 0.19$ & $0.84 \pm 0.60$ & $0.68 \pm 0.50$ & 0.00 & .670 \\
\cline { 2 - 7 } & $\mathbf{P}<0.05$ & - & .940 & .592 & .933 & .069 & . \\
\hline
\end{tabular}

$\mathrm{No}=$ number $\quad \mathrm{SE}=\mathrm{Standard}$ Error $\mathrm{CL}=$ corpus luteum

Table-3: Effect of CL on oocytes recovery, oocytes index, cleavage and blastocyst rates

\begin{tabular}{|c|c|c|c|c|c|c|c|c|c|c|}
\hline \multicolumn{2}{|c|}{ Factors } & \multirow{2}{*}{\begin{tabular}{|c|}
$\begin{array}{l}\text { No. of } \\
\text { ovaries }\end{array}$ \\
109 \\
\end{tabular}} & \multirow{2}{*}{$\begin{array}{l}\begin{array}{l}\text { No. of } \\
\text { Oocytes } \\
\text { recovery }\end{array} \\
145 \\
\end{array}$} & \multirow{2}{*}{$\begin{array}{c}\text { Oocytes } \\
\text { recovery } \\
\text { rate / ovary }\end{array}$} & \multirow{2}{*}{$\begin{array}{c}\begin{array}{c}\text { Oocytes } \\
\text { Index }\end{array} \\
2.35 \\
\end{array}$} & \multirow{2}{*}{$\begin{array}{c}\text { No. of Oocytes } \\
\text { for IVEP. I and II } \\
72\end{array}$} & \multirow{2}{*}{$\begin{array}{c}\begin{array}{c}\text { No. of } \\
\text { Cleavag } \\
\text { e }\end{array} \\
23 \\
\end{array}$} & \multirow{2}{*}{$\begin{array}{c}\text { Cleavag } \\
\text { e rate \% } \\
31.9 \\
\end{array}$} & \multirow{2}{*}{$\begin{array}{c}\begin{array}{c}\text { No. of } \\
\text { Blastocyst }\end{array} \\
1 \\
\end{array}$} & \multirow{2}{*}{$\begin{array}{c}\begin{array}{c}\text { Blasto } \\
\text { cyst } \\
\text { rate } \%\end{array} \\
1.3 \\
\end{array}$} \\
\hline CL & Present & & & & & & & & & \\
\hline & Absent & 187 & 335 & 1.7 & 2.23 & 207 & 55 & 26.6 & 1 & 0.5 \\
\hline
\end{tabular}

No= number $\mathrm{SE}=$ Standard Error $\%=$ percent $\mathrm{CL}=$ corpus luteum

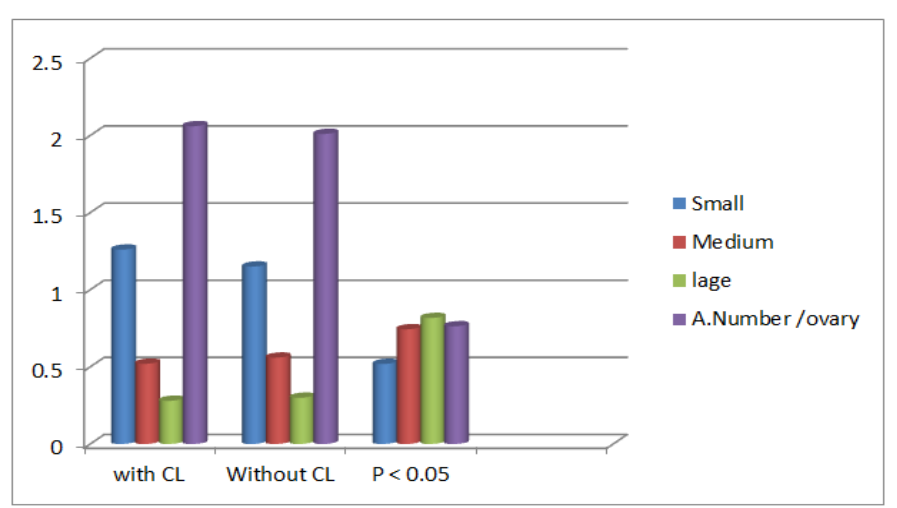

Relationship between Present or absent of $\mathrm{CL}$ and follicular population

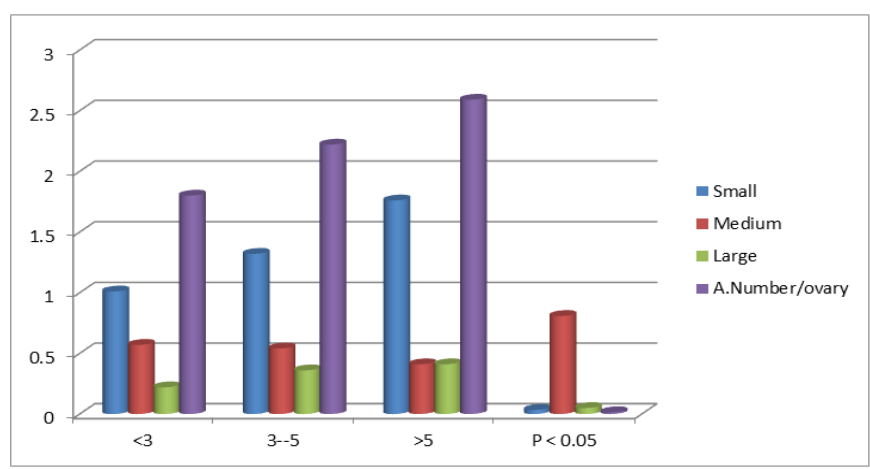

Relationship between ovary weight and follicular population 


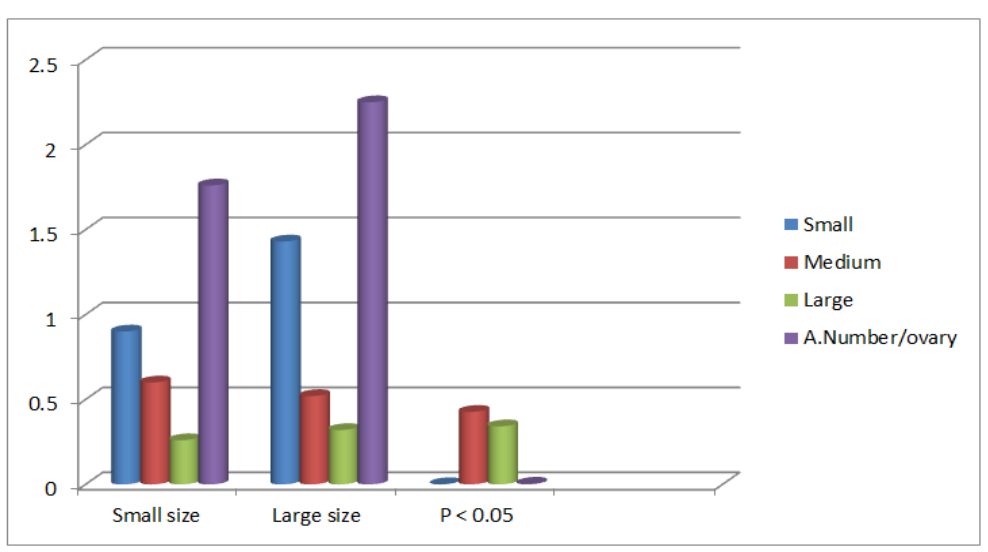

Relationship between ovary size and follicular population

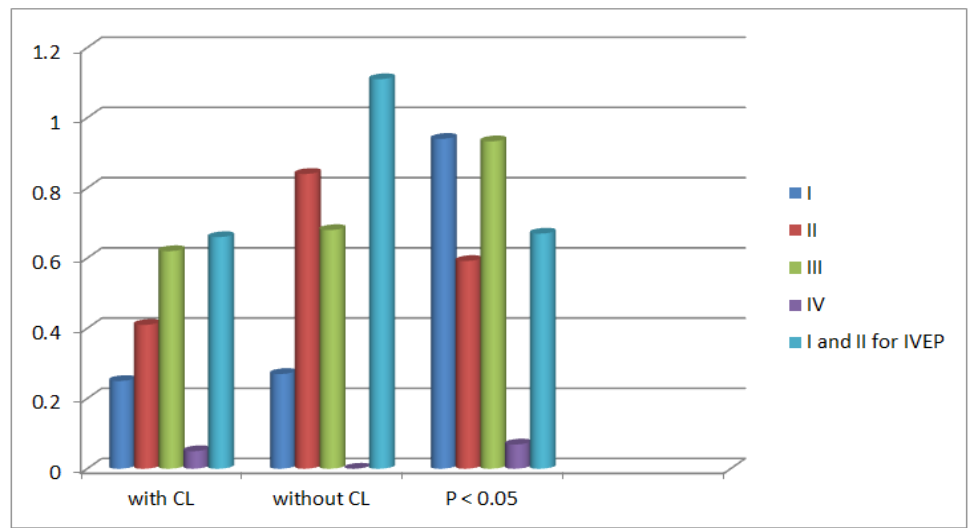

Relationship between present or absent $\mathrm{CL}$ and oocytes grades

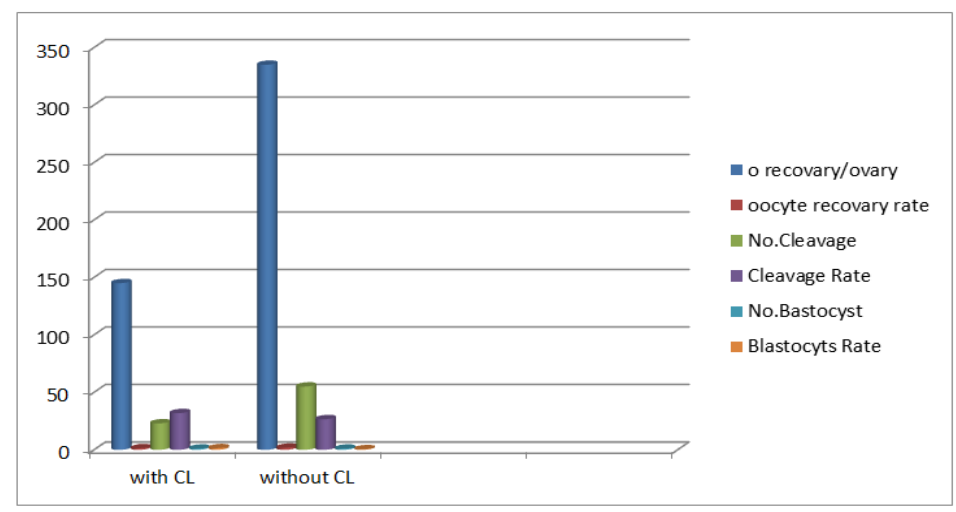

Effect of CL on cleavage and blastocyst rates

\section{Discussion}

The present study demonstrated that the number of small and large follicles were significantly higher in ovaries having weight more than $5 \mathrm{~g}$ as compared to ovaries weight $3-5 \mathrm{~g}$ and less than $3 \mathrm{~g}$. No significant effect was observed between number of medium follicles and ovary weight. This result simulate to that of found in cow heifers $[20,21]$, indicated that the variation in ovarian weight is not only due to the weight of antral follicles and CL but there is number of microscopic follicles and these follicles at least partially contributed to the weight of the ovary. The number of follicle per ovary was significantly higher $(P<.004)$ in ovaries have large size when compared with ovaries of small size. Our results are in agreement with early report of buffalo [11] and sheep [22]. This study demonstrated that no significant difference observed between presence or absence of $\mathrm{CL}$ and oocytes grades. The results are also similar to that reported in bovine [14].

The mean of oocyte recovery rate obtained from ovaries with $\mathrm{CL}(1.3 \%)$ was significantly lower than that ovary without $\mathrm{CL}$ (1.7\%). Our results is similar to that found in buffalo by Das et al., [23] and Raza et al., [24] and they reported that the presence of a $\mathrm{CL}$ significantly reduces the number of ovarian follicles as well as the quality of oocytes in buffaloes. Because the follicular 
development is restricted as lutein cells occupy most of the ovary [25]. Different studies have reported $0.4-3.85$ good oocyte/ ovary in buffalo [26].

This variation is due to the different methods used for COC recovery, seasonal effects, and variation in the reproductive status of the slaughtered buffaloes. However, when compared to cattle (10 oocyte lovary) [27].The number of good oocyte/ovary in buffalo is lower which may be due to an inherently smaller number of primordial follicles and a higher frequency of atresia in buffalo [28]. Further, the percentages of cleavage and blastocyst were lower as compared with the number of oocytes recovery. This result may be due to the effect of time taken on measuring the weight and size of the ovaries on the quality of oocytes.

\section{CONCLUSION}

This study revealed that the number of small and large follicles were significantly higher in ovaries having weight more than $5 \mathrm{~g}$ as compared to ovaries weight between $3-5 \mathrm{~g}$ and less than $3 \mathrm{~g}$. The number of small follicles in large size ovaries was higher than small size ovaries. The number of oocytes recovery, number of oocytes for IVEP and number of cleavage, obtained from ovaries with $\mathrm{CL}$ was lower than that of ovaries without CL. The buffaloes ovaries have a good potential for IVEP but less than cattle.

\section{ACKNOWLEDGEMENTS}

The author thanks the CIRB administration for allow him to did this research in the buffalo's farm and CV Raman fellowship for support this research.

\section{REFERENCES}

1. Munjunatha, B. M., \& Devaraj, M. (2006). Ovum pickup and in vitro embryo production in buffaloes and cattle: an alternative to the conventional embryo production approach. ICAR Winter School on Reproductive Techniques to Augment Fertility in Dairy Animals, 96-99.

2. Hernandez-Fonseca, H. J., Sirisathien, S., Bosch, P., Cho, H. S., Lott, J. D., Hawkins, L. L., Hollett, R. B., Coley, S. L., \& Brackett, B. G. (2002). Offspring resulting from direct transfer of cryopreserved bovine embryos produced in vitro in chemically defined media. Animal Reproductive Science, 69:151-158.

3. Deleuze, S., Goudet, G., Caillaud, M., Lahuec, C., \& Duchamp, G. (2009). Efficiency of embryonic development after IntraFollicular and Intra-Oviduct transfer of in vitro and in vivo matured horse oocytes. Theriogenology, 72: 203-209.

4. Seidel, G. E., \& Seidel, S. M. (1989). Analysis of application of embryo transfer in developing countries. Theriogenology, 31(1): 3-16.

5. Huang, Y. J., \& Rosenwarks, Z. (2012). In vitro fertilization treatment and factors affecting success. Best Practice Resource. Clinical Obstetric. Gynecology, 26: 777-788.

6. Kumar, D., \& Anand, T. (2012). In Vitro Embryo Production in Buffalo: Basic Concepts. Journal of Buffalo Science, 1:50-54.

7. Galli, C., \& Lazzari, G. (2008). The manipulation of gametes and embryos in farm animals. Reproductive In Domestic Animals, 43: $1-7$.

8. Niemann, H., \& Wrenzycki, C. (2000). Alterations of expression of developmentally important genes in preimplantation bovine embryos by in vitro culture conditions: implications for subsequent development. Theriogenology, 53: 21-34.

9. Hasler, J. F. (2003). The current status and future of commercial embryo transfer in cattle. Animal Reproductive Science, 79: 245-264.

10. Dharmendra, K., Anand, T., Singh, K. P., Singh, M. K., Shah., R. A., Chauhan, M. S., Palta, P., Singla, S. K., \& Manik, R. S. (2011). Derivation of buffalo embryonic stem-like cells from in vitro-produced blastocyst on homologous and heterologous feeder cells. Journal of Assisted Reproductive Genetic, 28:679-688.

11. Samad, H. A., \& Raza, A. (1999). Factors affecting recovery of buffalo follicular oocytes. Pakistan Veterinary Journal. 19: 56-59.

12. Bukar, M. M., Amin, J. D., Sivachelvan, M. N., \& Ribadu, A. Y. (2006). Postnatal histological development of the ovaries and uterus and the attainment of puberty in female kid goats. Small Ruminant Research, 65:200-208.

13. Razzaque, W. A. A., Sahatpure, S. K., Pawshe, C. H., \& Kuralkar, S. V. (2008). Biometry of ovaries and follicular count in cycling and non cycling Nagpuri buffaloes (Bubalus Bubalis). Journal of Buffalo Bulletin, 27(1):150-153.

14. Kouamo . J, Dawaye. S.M , Zoli. A.P. and Bah. G.S. (2014). Evaluation of bovine (Bos indicus) ovarian potential for in vitro embryo production in the Adamawa plateau (Cameroon), Open Veterinary Journal, 4(2): 128-136.

15. Acar, D. B., Birdane, M. K., Dogan, N., \& Gurler, H. (2013). Effect of the stage of estrous cycle on follicular population, oocyte yield and quality, and biochemical composition of serum and follicular fluid in Anatolian water buffalo. Animal reproduction science, 137(1-2), 8-14.

16. Alves, T., \& Felton, D. (2014). TrustZone: Integrated Hardware and Software Security-Enabling Trusted Computing in Embedded Systems (July 2004).

17. Laine, L., Abid, S., \& Albillos, A. (2011). Portal Hypertension V: Proceedings of the Fifth Baveno International Consensus Workshop.

18. De Loos, F., Van Beneden, T., Kruip, T. A. M., \& Van Maurik, P. (1992). Structural aspects of bovine oocyte maturation in vitro. Molecular reproduction and development, 31(3), 208-214. 
19. Linder, P. W., Torrington, R. G., \& Seemann, U. A. (1983). Formation constants for the complexes of levulinate and acetate with manganese (II), cobalt (II), nickel (II), copper (II), zinc (II) and hydrogen ions. Talanta, 30(4), 295-298.

20. Cushman, R. A., Desouza, J. C., Hedgpeth, V. S., \& Britt, J. H. (1999). Superovulatory response of one ovary is related to microand macroscopic population of follicles in contra lateral ovary of cow, Biology of reproduction, 60: 349-354.

21. Maya, M., Tsuyoshi, T., Hiromi, N., Sawa, Y., Seizo, H., \& Masafumi, T. (2005). The relationship between ovarian weight and follicular population in heifers. Journal of reproduction and development, 51: 689-693.

22. Wani, A. N. (1995). In vitro maturation and in vitro fertilization of ovine oocytes. MVSc thesis, Faculty of postgraduate studies Sher-e -Kashmir University of Agricultural Science and Technology, Srinagar.

23. Das, G. K., Jain, G. C., Solanki, V. S., \& Tripathi, V. N. (1996). Efficacy of various collection methods for oocyte retrieval in buffalo. Theriogenology, 46: 1403-1411.

24. Raza, A., Samad, H. A., Rehman, N. U., \& Zia, E. U. H. (2001). Studies on in vitro maturation and fertilization of Nili-Ravi buffalo follicular oocyte. International Journal of Agriculture and Biology. 3: 503-506.

25. Kumar, G. (1997). Geology of Arunachal Pradesh. GSI Publications, 2(1).

26. Nandi, S, G., Kumar, V., \& Chauhan, M. S. (2006). In vitro production of bovine embryos: We need to stop or proceed - a review. Agricultural. Review, 27(2):122-129.

27. Greve, T., \& Madison, V. (1991). In vitro fertilization in cattle: a review. Reproduction Nutrition. Development, 31: 147-157.

28. Drost, M. (2007). Bubaline versus bovine reproduction. Theriogenology, 68: 447-449. 